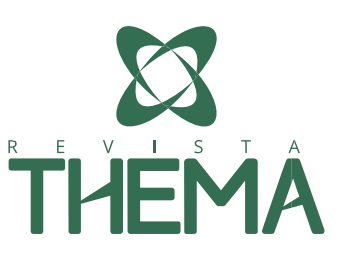

\title{
Ambiente Virtual de Aprendizagem Orientado à Legislação: Um Estudo de Caso na Gestão da Educação Profissional a Distância
}

\section{Legislative Virtual Learning Environment: A Case Study in the Management of Distance Professional Education}

Maria Isabel Giusti Moreira 1; Antônio Carlos da Rocha Costa²; Marilton Sanchotene de Aguiar $^{3}$

\section{RESUMO}

Na Educação a Distância apoiada pelas tecnologias digitais, os Ambientes Virtuais de Aprendizagem são softwares constituídos por interfaces que favorecem o processo de ensino e de aprendizagem por meio da Internet. Observa-se, no entanto, que os diferentes Ambientes Virtuais de Aprendizagem existentes possuem recursos e ferramentas voltados ao processo educativo, não contemplando, porém, aspectos relativos à gestão na Educação a Distância. Este trabalho apresenta um estudo de caso ao implementar suporte à gestão no AVA MOODLE, possibilitando a incorporação de leis e normas que regem a Educação a Distância de um Instituto Federal por meio de Inteligência Artificial em sua customização a partir de Sistemas Multiagentes.

Palavras-chave: Sistemas Multiagentes, Modelos Organizacionais, Ambiente Virtual de Aprendizagem, Educação a Distância

\begin{abstract}
In Distance Education supported by digital technologies, Virtual Learning Environments are software made up of interfaces that favor the process of teaching and learning through the Internet. It is observed, however, that the different Virtual Learning Environments exist have resources and tools focused on the educational process, but do not contemplate aspects related to Distance Education management. This work presents a case study when implementing management support in Virtual Learning Environments MOODLE, enabling the incorporation of laws and norms that govern the DE of a Federal Institute through Artificial Intelligence in its customization from Multi-Agent Systems.
\end{abstract}

Keywords: Multi-Agent Systems, Organizational Models, Virtual Learning Environments, Distance Education

\footnotetext{
${ }^{1}$ UFRGS - Universidade Federal do Rio Grande do Sul, Porto Alegre/RS - Brasil

2 UFRGS - Universidade Federal do Rio Grande do Sul, Porto Alegre/RS - Brasil

3 UFPel - Universidade Federal de Pelotas, Pelotas/RS - Brasil
} 


\section{INTRODUÇÃO}

A Educação a Distância (EaD) é uma modalidade educacional em que a mediação pedagógica ocorre com apoio de meios e Tecnologias de Informação e Comunicação (TICs), na qual os atores envolvidos podem ensinar e aprender em lugares e tempos distintos.

Em muitos países, como no Brasil, a EaD tornou-se uma possibilidade para democratizar a educação, permitindo a inclusão social visto que consegue atingir locais onde não existem Instituições de Ensino (IE), por meio da Internet.

No Brasil, a EaD é regida por bases legais que foram estabelecidas pela Lei de Diretrizes e Bases da Educação Nacional (Lei no. 9.334), e regulamentada pelo Decreto no. 5.622, com normatização definida na Portaria Ministerial no. 4.361, de 2004. A legislação que ampara a EaD também regulamenta e determina suas ações e funções, visto que um dos grandes desafios é fazer com que as IE atendam às exigências pedagógicas, garantindo segurança e qualidade em todo o processo educativo desenvolvido nessa modalidade.

A tecnologia digital que permitiu o avanço da $\mathrm{EaD}$ foi o desenvolvimento de espaços virtuais focados para essa modalidade de ensino denominados de Ambientes Virtuais de Aprendizagem (AVA). Entretanto, a popularização da EaD e o crescente número de atores envolvidos nesse processo, fizeram com que emergissem algumas deficiências relacionadas ao processo de gestão acadêmica e administrativa nessa modalidade de ensino enquanto apoiada por AVAs.

Na gestão corporativa ou institucional, que envolve questões de cunho administrativo, os AVAs existentes atualmente, não apresentam nenhum tipo de suporte, assim como, atuam de forma distanciada das leis, normas e regulamentações que o governo e as próprias IEs determinam para o bom andamento da EaD. Sendo assim, os AVAs são incapazes de aplicar a seus atores as regulamentações que estão em vigência, condicionando as ações que estes realizam no ambiente àquelas normas.

Este estudo propõe uma alternativa para a deficiência de suporte à legislação nos AVAs ao possibilitar a incorporação de leis e normas que regem a EaD em sua customização, visando auxiliar nas tarefas relacionadas à gestão institucional. Neste sentido, o objetivo deste trabalho é apresentar uma proposta de customização de um modelo que permita integrar no AVA MOODLE conceitos de um Sistema Jurídico, controlado por Inteligência Artificial através de Sistemas Multiagentes (SMA)4. O estudo propõe o desenvolvimento de um conceito denominado de Sistema AVA-SMA orientado à Legislação, que permita incorporar leis e normativas para o AVA, com certo grau de autonomia.

Visto que uma forma de instrumentalizar a interação de agentes em um SMA é através da utilização de uma estrutura organizacional, foi utilizado uma adaptação do modelo organizacional Moise ${ }^{+5}$ que permitiu definir os comportamentos dos atores envolvidos no processo de EaD, regulamentando as restrições e as permissões definidas por leis e normativas.

\footnotetext{
${ }^{4}$ Um conjunto de agentes que interagem em um ambiente comum.

${ }^{5}$ Padrão que descreve como os membros pertencentes a uma sociedade estão em relação aos outros e como irão interagir para atingir um objetivo comum (FOX et al., 1992).
} 
Para a formalização desse modelo foi utilizado como estudo de caso a modalidade de EaD desenvolvida por um Instituto Federal (IF), que oferta cursos de nível técnico, superior e formação continuada nessa modalidade de ensino, por meio do AVA MOODLE.

Esse trabalho dará apoio aos gestores de programas do IF, onde hoje todo o processo de gestão fica fora de sistemas oficiais (como os ambientes virtuais de aprendizagem), além de serem feitos de forma manual, o que demanda um grande tempo desperdiçado, gerando uma enorme quantidade de papéis que muitas vezes se perdem ao longo do tempo.

\section{AMBIENTES VIRTUAIS DE APRENDIZAGEM}

No início dos anos 90, dentro das principais $\mathrm{IE}$, começaram a surgir as primeiras tecnologias de software com foco na EaD. O trabalho realizado por essas IEs estava voltado para a necessidade de encontrar maneiras de reunir recursos de interação digital com páginas de conteúdo criadas por professores, bem como o armazenamento de atividades realizadas por alunos (MUNHOZ, 2011).

Os Ambientes Virtuais de Aprendizagem (AVA) surgiram com a finalidade de gerenciar o processo de ensino e de aprendizagem, agregando interfaces para permitir a geração de conteúdos com base nos mais variados meios de comunicação digital, possibilitando a utilização de recursos pedagógicos, numa tentativa de ampliar a sala de aula presencial para o meio virtual (BEHAR, OLIVEIRA E SCHNEIDER, 2004),

Britain e Liber (1999) definem um AVA como a combinação de um software de comunicação mediado por computador e de um método de entrega online de materiais dentro de um único ambiente de software.

O Ambiente de Aprendizagem Dinâmica Modular Orientada a Objetos (MOODLE) é um AVA que começou a ser desenvolvido no fim da década de 90 por Martin Dougiamas (DOUGIAMAS E TAYLOR, 2000).

Ao projetar o MOODLE, Dougiamas teve a ajuda de um pedagogo que sugeriu utilizar a ideia do construtivismo, afirmando que o ensino se torna eficaz quando construímos algo para os outros experimentarem, e do construtivismo social, o qual amplia a noção de grupo social que constrói o ensino uns com os outros, criando e compartilhando uma cultura de conteúdos e significados (DOUGIAMAS, 2003).

O MOODLE é um software livre, desenvolvido na linguagem $\mathrm{PHP}^{6}$ que armazena a maioria dos objetos de aprendizagem em uma base de dados SQL ${ }^{7}$. Possui uma estrutura modular de fácil desenvolvimento que permite que uma comunidade ajude em suas melhorias e adaptações.

Além disso, esse AVA possui características importantes, como: escabilidade, facilidade de uso, estabilidade, segurança, interoperabilidade, roda em multiplataformas e possui uma interface simples e interativa que pode ser personalizada de acordo com a IE.

\footnotetext{
6 Hypertext Preprocessor

7 Structured Query Language
} 


\section{SISTEMAS MULTIAGENTES E SEUS MODELOS ORGANIZACIONAIS}

Os SMA são sistemas computacionais constituídos de múltiplos agentes ${ }^{8}$ que interagem e trabalham em grupo para realizar um determinado conjunto de tarefas resolvendo um problema complexo.

A principal finalidade dos SMAs é a de permitir um comportamento global inteligente que possa ser alcançado através dos comportamentos individuais dos agentes que o compõe, baseado no comportamento social de uma comunidade formada por agentes autônomos (RUSSEL E NORVIG, 1995).

\subsection{Modelos Organizacional MOISE ${ }^{+}$para SMA}

Fox (1997) define uma organização como um padrão que descreve como os membros pertencentes a uma sociedade estão em relação aos outros e como irão interagir para atingir um objetivo comum.

A organização de SMA é um conjunto de restrições aos comportamentos dos agentes, a fim de conduzir os mesmos a um objetivo comum. Existem vários tipos de modelos organizacionais, porém o modelo escolhido para servir de base para o desenvolvimento deste trabalho foi o Model of Organization for Multi-Agent ${ }^{+}$(Moise $^{+}$), desenvolvido por Hubner, Sichman e Boissier (2002).

O Moise ${ }^{+}$considera que o objetivo de uma organização é o de restringir a autonomia do agente. As restrições expressas no Moise ${ }^{+}$são indicados através das permissões de obrigação e proibição.

O Moise $^{+}$trabalha com a organização de um SMA baseado em três dimensões: a especificação estrutural (papéis), a estrutura funcional (planos globais) e a especificação deôntica (obrigações) da organização.

A especificação estrutural (EE) é baseada em três conceitos principais, conforme Hubner, Sichman e Boissier (2002): os papéis que são um conjunto de restrições comportamentais que uma agente aceita ao entrar em um grupo; as ligações e compatibilidades onde os papéis estão relacionados a outros representando restrições impostas às interações; e os grupos que representam um conjunto de agentes com afinidades maiores e objetivos mais próximos.

Já a especificação funcional (EF) é constituída por um conjunto de esquemas sociais, além de uma relação de preferência entre missões. Um esquema social é baseado na ideia de metas globais, cuja função é representar um estado de mundo que é desejado pelo SMA (HUBNER, SICHMAN E BOISSIER, 2004).

A cada meta global é associado uma combinação de três valores: nível de satisfação: indica se a meta já foi atingida ou não; nível de alocação: indica se já existe ou não algum agente comprometido a satisfazer a meta; nível de ativação: indica se as pré-condição necessárias para que a meta seja satisfeita estão presentes.

Os principais conceitos relacionados com as metas globais são (HUBNER, SICHMAN E BOISSIER, 2002):

\footnotetext{
8 Um agente é um sistema computacional que está situado em algum ambiente e que é capaz de agir de forma autônoma nesse ambiente para alcançar seus objetivos projetados (WOOLDRIDGE, 2002).
} 
- Missões: é um conjunto de metas globais que podem ser atribuídas a um agente através de seus papéis;

- Esquema social: é uma árvore de decomposição de metas globais onde a raiz é a meta do esquema social;

- Preferências entre missões: em alguns casos é necessário estabelecer uma ordem de preferencias entre missões.

A especificação deôntica (ED) tem como objetivo relacionar a especificação estrutural e a funcional, que é responsável por estabelecer quais missões que um papel tem permissão ou obrigação de se comprometer. Essa é representada por um tupla ${ }^{9}$ que inclui um conjunto de permissões que determina se um agente possui um determinado papel e um conjunto de obrigações que estabelece se um agente é obrigado a se comprometer com a missão (HUBNER, SICHMAN E BOISSIER, 2004).

\section{TEORIA DE SISTEMAS JURÍDICOS DE KELSEN}

Incorporar SMA aos AVA, bem como trabalhar com normatividade dentro de sistemas sociais humanos ainda é um desafio existente dentro da área da Inteligência Artificial. Porém, utilizar essas noções normativas, como a obrigação, dever e proibição, facilita a concepção, bem como a especificação de sistemas de computação, tornando-os mais autônomos.

Baseado nessa questão, torna-se fundamental apresentar as questões relacionadas a normatividade baseado na Teoria de Sistemas Jurídicos proposto por Hans Kelsen, um dos mais importantes juristas e filósofos austríaco do século XX.

Uma norma é algo que deveria existir ou ser feito para que adquira um sentido objetivo de dever/ser, destacando seu caráter imperativo, tanto de imposição como de proibição e outras funções deôntica.

Dentro das inúmeras classificações possíveis, em Kelsen (2009), destacam-se dois tipos de normas que se referem à generalidade ou a individualidade e a relação com as suas funções.

A norma individual prescreve um comportamento ou conduta única e individualmente obrigatória. Já uma norma geral determina uma conduta universal que é posta como devida.

Cada vez que uma norma é criada verifica-se o sentido do dever/ser, na qual a primeira parte da norma destaca o que se deseja do outro e a quem ela foi imposta.

\subsection{Norma Jurídica}

Uma norma jurídica determina como se comportar em determinadas condições, ou seja, se um comportamento e as relações sociais podem ser prescritas, proibidas ou autorizadas. Uma norma jurídica indica tanto uma conduta ou uma omissão de uma conduta que deve ser evitada pelos sujeitos agentes do sistema jurídico, quanto uma sanção que deve ser aplicada a um agente sujeito no caso deste realizar a conduta.

\footnotetext{
${ }^{9}$ Uma sequência ordenada de $\mathrm{n}$ elementos.
} 
Segundo Kelsen (2009), as funções da norma jurídica se dividem em normas de: imposição, onde toda a proibição em uma norma dever/ser é vista como uma norma de imposição; permissão que é caracterizada pela proibição de se impor ou de proibir uma certa conduta; autorização confere a um agente o poder de estabelecer e aplicar normas; derrogação é aquela que extingue a validade ou existência de outras normas.

As normas jurídicas formam um sistema normativo que requer que os envolvidos estejam em conformidade com os modos de comportamentos nela declarados. Para isso, utiliza-se um sistema jurídico.

\subsection{Norma Jurídica}

Um sistema jurídico é basicamente uma hierarquia de normas que pertencem a um conjunto interrelacionado. Cada norma é derivada de uma norma superior, cuja sua base é uma norma jurídica. Segundo Kelsen (2009), existem dois tipos de sistemas jurídicos: estáticos que são constituídos por normas que se deduzem uma das outras, tendo como base o seu conteúdo e os dinâmicos que são constituídos por normas que se produzem umas por meio das outras, mediante uma relação de delegação de um poder superior a outro inferior.

Cada norma válida de uma ordem jurídica deve ser especificada em quatro domínios de validade: espaço e tempo: especificam o contexto em que a norma é aplicável; destinatários e condutas: especificam os tipos de envolvidos e os tipos de conduta que a norma se refere; órgão jurídico: funciona como agentes que são autorizados por atos jurídicos válidos; ato jurídico: é uma performance de conduta pela qual os órgãos jurídicos, que executam a conduta, possam ter uma autorização válida para realizar a execução, ou seja, é um ato de vontade.

\section{MODELO ORGANIZACIONAL PARA SMA ORIENTADO A LEGISLAÇÃO}

Para formalização de um modelo organizacional para SMA capaz de integrar aspectos legais, tornando o SMA orientado a legislação, foi utilizada uma variação do modelo organizacional Moise ${ }^{+}$pelo fato de que esse modelo possibilita restringir os comportamentos dos agentes.

A fim de desenvolver este estudo de caso em um modelo organizacional para SMA, foi realizado um levantamento das leis, normativas, regimentos internos e externos, bem como contratos que são utilizados pela EaD do IF.

\subsection{Atores da modalidade EaD}

A EaD no Brasil é incentivada por dois programas de governo que hoje fomentam cursos de EaD, programas esses denominados de Universidade Aberta do Brasil (UAB) e de Rede e-Tec Brasil (eTec).

A Rede e-Tec tem como foco a oferta de cursos técnicos na modalidade a distância, além de formação inicial e continuada de trabalhadores egressos do ensino médio ou da educação de jovens e adultos que tem como foco desenvolver, ampliar e democratizar o acesso a Educação Profissional e Tecnológica exclusivamente na modalidade a distância. 
No IF ligado a Pró-reitora de Ensino, estão as ações que envolvem a EaD, que atualmente realizam o planejamento e a normatização das atividades de ensino realizadas nessa modalidade de ensino. Ligados à Pró-reitora de Ensino, estão os dois programas de governo que ofertam curso na modalidade a distância: e-Tec e UAB.

Ambos os programas possuem um coordenador geral, que atua nas atividades de coordenação e apoio aos polos, e um coordenador geral adjunto, que tem a função de apoiar o coordenador geral nessas ações. Esses atores recebem o auxílio de uma equipe multidisciplinar, composta por professores de diversas áreas.

No campus existem os departamentos ou as coordenações de EaD, composta pelos seguintes atores:

- Coordenador do Curso: é um professor com formação em área relacionada ao curso e responsável pelo seu gerenciamento;

- Professor Formador: é um professor com formação em área específica relacionada, cujo papel é planejar e gerenciar todo o processo de desenvolvimento da aprendizagem na disciplina;

- Revisor Pedagógico: é um profissional cujo objetivo é auxiliar em todo o acompanhamento pedagógico do curso;

- Revisor Linguístico: é um professor responsável pela revisão de linguagem, semântica e ortografia dos materiais didáticos;

- Equipe TI: têm como principal objetivo dar suporte tecnológico para os cursos;

- Secretaria: têm como principal finalidade auxiliar os demais atores dando apoio à estrutura da coordenação;

- Coordenador de Professores Mediadores: sua função é realizar a comunicação e a interação com os professores mediadores presenciais e a distância;

- Professores Mediadores a Distância: faz o acompanhamento das atividades realizadas online pelos estudantes, tirando dúvidas e corrigindo tarefas;

- Professores Mediadores Presencial: é o responsável pela orientação e acompanhamento dos estudantes no polo;

- Coordenador de Polo: deve ser um professor da rede pública, graduado e com no mínimo três anos em magistério na educação básica ou superior. É o intermediário entre o Município e as IEs e responsável pela administração do polo.

\subsection{Especificação Estrutural (EE)}

Baseado nestes atores, propomos a criação da EE através de um conjunto de papéis dos atores envolvidos com o processo de EaD do IF. Nesta EE são apresentados os papéis, grupos e as relações entre eles.

A EaD do IF possui vários agentes comprometidos com o papel abstrato de coordenador. Estes são: um coordenador de polo, de curso, de tutoria, geral ou geral adjunto, bem como geral de campus. 
Já os agentes comprometidos com o papel abstrato professor podem ser um professor conteudista ou pesquisador. Além disso, um professor pode fazer parte da equipe multidisciplinar da Rede e-Tec.

Os agentes que assumem o papel abstrato de professor mediador podem ser divididos em: professor mediador presencial e a distância. Existe também o papel abstrato do revisor que pode se dividir em: revisor linguístico e pedagógico. Além destes papéis, temos os agentes denominados funcionários que atendem a secretaria ou a um grupo de apoio.

Além dos papéis citados, existe um conjunto de papéis que assumem um nível coletivo formando assim os grupos.

A EaD do IF está vinculada ao MEC, no qual há seis grupos $\mathrm{SETEC}^{10}, \mathrm{DDR}^{11}$ e, $\mathrm{PRONATEC}^{12}$.

Como o IF apresenta os dois programas vinculados ao Governo Federal, temos mais dois grupos chamados de UAB e Rede e-Tec.

Finalizando a modelagem organizacional da $\mathrm{EE}$, em relação ao campus temos os seguintes grupos: Coordenação EaD, Secretaria, Polo, Equipe de Apoio e Equipe de TI.

\subsection{Funções}

Cada um dos papéis possuem um conjunto de funções que são normatizadas pela Lei no. 9.394/1996. Além das leis estabelecidas pelo MEC, o IF possui um conjunto de normativas que determinam o funcionamento que deve ser realizado pelos atores envolvido na EaD.

Em virtude da grande diversidade de funções, neste trabalho será apresentado apenas as definições do papel do Coordenador de Curso.

Um coordenador de curso está diretamente vinculado ao coordenador da Coordenadoria de EaD de um campus.

\subsection{Especificação Funcional (EF)}

O objetivo da EF é ser responsável por caracterizar o foco funcional de uma organização, sendo denominado, assim, de esquemas sociais.

Esses esquemas são compostos por um conjunto de metas globais, estruturadas em uma árvore de decomposição por meio de planos globais. Sendo assim, propôs-se a EF com objetivos, planos e missões do papel do Coordenador de Curso.

Para representar, dentro do modelo adaptado do Moise $^{+}$, esse esquema social, foi utilizada uma tabela e uma árvore de decomposição da meta, que é feita por planos que indicam uma forma de satisfazer essa meta. Nesse caso, a raiz da árvore é a meta do esquema social a ser atingida.

\footnotetext{
${ }^{10}$ Secretaria de Educação Profissional e Tecnológica do Ministério da Educação (Setec/MEC)

${ }_{11}$ Diretoria de Desenvolvimento da Rede Federal de Educação Profissional, Científica e Tecnológica

12 Programa Nacional de Acesso ao Ensino Técnico e Emprego (Pronatec)
} 
As missões estipuladas para a EF determinam a ordem em que os planos devem ocorrer para que consigam atingir o objetivo específico. O conjunto de vários planos que formam a árvore do esquema, determina as condições de coordenação entre as atividades dos agentes.

Na Tabela 1 está representada a decomposição de planos que se deve realizar para se completar a meta RealProf e a determinação de como será a coordenação desses planos entre os agentes, bem como a descrição da mesma.

\begin{tabular}{|l|l|c|}
\hline \multicolumn{1}{|c|}{ Meta } & \multicolumn{2}{c|}{ RealProf } \\
\hline Planos & Descrição & Missões \\
\hline APROVADO & o candidato é aprovado no processo de seleção & $\mathrm{m}_{3}$ \\
\hline DOCPRAZO & a documentação é recebida no prazo do edital & $\mathrm{m}_{1}$ \\
\hline DOCOK & a documentação está completa & $\mathrm{m}_{2}$ \\
\hline APROVADOBOLSA & $\begin{array}{l}\text { a documentação é aprovada pela coordenação Geral da Rede e-Tec } \\
\text { Brasil no IF para o recebimento da bolsa }\end{array}$ & $\mathrm{m}_{3}$ \\
\hline TEMDOC & o candidato tem toda a documentação necessária solicitada no edital & $\mathrm{m}_{1}$ \\
\hline TEMDISC & o candidato tem habilidades e competências para ministrar a disciplina & $\mathrm{m}_{1}$ \\
\hline INSC & inscrição realizada & $\mathrm{m}_{1}$ \\
\hline SUBELE & submissão via e-mail & $\mathrm{m}_{1}$ \\
\hline REUNIAO & participar de reunião com o candidato & $\mathrm{m}_{3}$ \\
\hline ACESSOAVA & liberar o acesso ao AVA & $\mathrm{m}_{3}$ \\
\hline ENTREVISTA & realizar entrevista com o candidato a seleção & $\mathrm{m}_{2}$ \\
\hline AVALCUR & avaliar o currículo do candidato & $\mathrm{m}_{2}$ \\
\hline
\end{tabular}

Tabela 1. Planos da meta RealProf para organizar a coordenação entre os agentes

Fonte: Elaborado pelo autor.

A Figura 1 apresenta um esquema social para a meta RealProf com os planos e missões que os agentes devem cumprir para realizá-la.

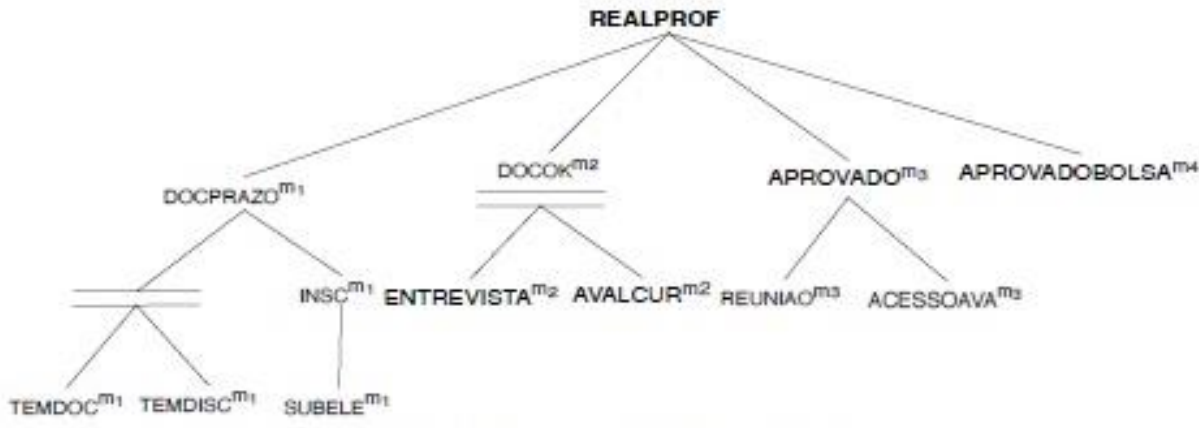

Figura 1. Esquema Social - Meta RealProf Fonte. Elaborado pelo autor.

\subsection{Normas Contratuais e Regimentais}

Com base nos regimentos internos do IF e nas normas contratuais desenvolvidas pelos programas, podemos definir os deveres, direitos e obrigações que devem ser executadas especificamente pelo 
Coordenador de Curso, que são apresentados no Termo de Compromisso do Bolsista da Rede e-Tec Brasil.

Os direitos de um Coordenador de Curso são: receber a bolsa enquanto desenvolver as atividades próprias de sua função; ter acesso ao AVA; participar das atividades de capacitação e atualização.

Já os deveres desse ator são: realizar o registro das avaliações desenvolvidas pelos alunos; manter interlocução com os coordenadores e demais professores no planejamento e execução das atividades inerentes aos cursos; participar das atividades desenvolvidas na instituição de ensino; manter a interlocução permanente com o MEC; coordenar a elaboração do projeto do curso; acompanhar as atividades acadêmicas do curso; participar do grupo de trabalho para o desenvolvimento de metodologia e materiais didáticos para a modalidade a distância.

\subsection{Especificação Deôntica do Modelo Organizacional}

Com o objetivo de interligar a EE e a EF e incluir as normas contratuais e regimentais no modelo organizacional temos os aspectos deôntica ${ }^{13}$ representados através de uma variação da Especificação Deôntica (ED) do modelo Moise ${ }^{+}$. Deste modo, podemos determinar quais são as responsabilidades dos papéis nos planos globais através das missões.

Nessa adaptação da Especificação Deôntica, temos a definição do papel que será responsável por realizar aquelas ações (representados na linha da tabela denominada Papel), o nome das ações que ele irá realizar (representado na coluna Nome da Ação), a descrição das metas (representados na coluna Descrição da Ação) e a legislação onde a mesma é encontrada. Já a relação deôntica desse modelo é estipulada por três conceitos: dever, direito e a proibição de realizar a missão, conforme a coluna Restrição Deôntica.

Por fim, temos a coluna com a restrição temporal, visto que as relações deôntica passam a ter um tempo de validade. Além disso, foi inserido duas colunas denominadas: de Quem controla ação e Quem participa da ação, que determinam quais papéis irão monitorar a ação e aplicar punições, e quem deverá ajudar para que a ação atinja seu objetivo.

\section{MODELO DE SISTEMA AVA-SMA ORIENTADO A LEGISLAÇÃO}

Para modelar e elaborar o sistema de um AVA e SMA orientado à legislação, tomou-se como base alguns aspectos fundamentais do modelo sistemático e hierárquico da $\mathrm{EaD}$ do IF, bem como as abordagens instrumentais determinados através da SETEC/MEC.

O modelo Sistema AVA-SMA orientado à Legislação proposto é composto por dois subsistemas (Sistema Legislador e Sistema de Sociedade), conforme mostra a Figura 2, onde os componentes, sua organização e principalmente suas funções serão detalhadas a seguir.

${ }^{13}$ É um tipo de lógica modal usada para analisar formalmente as normas ou as proposições que tratam acerca das normas. 


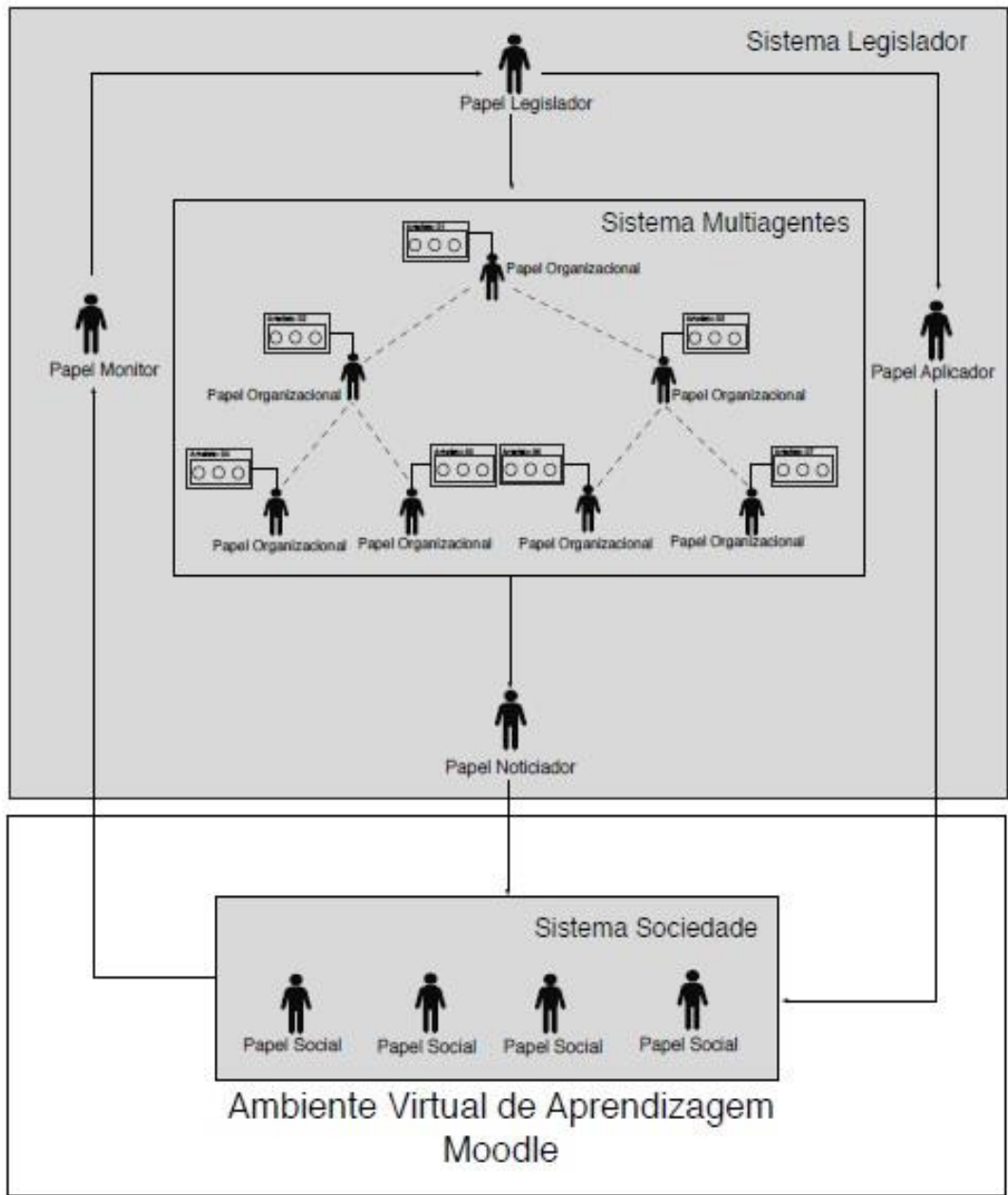

Figura 2. Esboço do Modelo de Sistema AVA-SMA orientado à Legislação Fonte. Elaborado pelo autor.

\subsection{Sistema de Sociedade}

O sistema de sociedade está integrado ao Moodle, e por esse motivo utiliza sua base de dados com os usuários, bem como perfis que estão cadastrados.

O sistema de sociedade irá permitir que os usuários façam suas ações normalmente para que o sistema legislador possa monitorar e verificar a legalidade dessas atividades. Pode-se dizer que essa parte do sistema é o MOODLE, em si.

Dentro do Sistema de Sociedade temos vários papéis denominados de Agentes Sociais sem hierarquia. Esses agentes sociais que compõem uma sociedade assumem papéis ou grupo de papéis.

Nesse caso, esse sistema é dividido em diversas categorias, sendo que um usuário pode assumir diferentes papéis, onde, por exemplo, um professor pode ser membro da equipe multidisciplinar ou o professor que irá ministrar uma disciplina.

Sendo assim, os usuários do Moodle podem assumir diversos papéis sociais, que terão de realizar suas funções normalmente no Moodle, como por exemplo, assumir o papel de professor formador ou mediador.

Ao ser cadastrado no MOODLE, o usuário já terá sido atribuído a um papel social de acordo com a função que irá realizar no sistema. 


\subsection{Sistema Legislador}

O sistema legislador terá como finalidade monitorar todas as ações realizadas no sistema de sociedade a fim de garantir que os agentes estejam atuando dentro da legalidade. No caso dos papéis sociais não estarem sendo cumpridos com suas metas, o sistema fica responsável de enviar notificações, bem como aplicar penalidades.

Ainda dentro do sistema legislador estará incluído uma sociedade de agentes baseada no modelo organizacional apresentado anteriormente, que trabalhará com a hierarquia de papéis ou grupos de papéis.

O sistema legislador será formado por quatro principais papéis que serão considerados como agentes de software, que irão interagir entre si a fim de monitorar e avaliar o andamento das ações e metas que estão ocorrendo dentro do sistema de sociedade.

O primeiro papel é denominado de papel legislador, que é responsável por realizar as ações de criar, modificar e remover normas e planos do SMA, sendo considerado um emissor de normas. Neste caso, o papel legislador será soberano sobre as normas, sendo assim, todas as tarefas de criar, modificar e remover normas, fica a cargo desse único papel.

O segundo papel é chamado de papel monitor, cuja sua finalidade é auxiliar na extração e captação de informações do que está ocorrendo no sistema de sociedades. Esse agente fica observando em tempo real as ações do sistema para verificar se os demais agentes estão cumprindo com as normas e planos.

Os papéis de monitores podem ser classificados em dois tipos:

- Monitores de Normas ou Artefatos: observam as normas e o comportamento dos papéis sociais, captando informações referentes ao cumprimento ou não desses normas.

- Monitores de Sociedade: captam informações sobre o estado corrente dos papéis sociais, garantido a execução dos planos que devem ser realizados para se atingir as metas.

Nesse caso, o sistema legislador poderá possuir no mínimo dois agentes monitores.

O terceiro papel é o papel noticiador que tem como objetivo principal apresentar lembretes (via bloco do AVA e e-mail) das ações pendentes ou de prazos a serem cumpridos antes de serem penalizados. Além disso, esse papel também terá a finalidade de mostrar onde foram baseadas as normas, ou seja, de qual lei, normativa, regimento ou contrato as normas foram baseadas e consequentemente extraídas. Nesse caso, o modelo irá se basear na Especificação Deôntica do SMA afim de buscar essas informações.

O notificador também, com base nos e-mails cadastrados no MOODLE, irá disparar mensagens aos usuários sobre pendências ou penalidades aplicadas aos agentes.

E por fim, o último agente é chamado de papel aplicador, e sua função é auxiliar na aplicação de normas e planos, bem como será responsável por aplicar as sanções e penalidades quando as normas não forem cumpridas de forma correta. 
O papel aplicador terá duas subdivisões:

- Aplicador de Sanções: realizam a efetiva aplicação de sanções e penalidades prescritas nas normas aos papéis sociais que a descumprem;

- Aplicador de Planos: executam os planos de ações e alteram as propriedades estruturais da sociedade.

Já os papéis do SMA, que estão localizados dentro do sistema legislador, serão os mesmos papéis utilizados no sistema de sociedade, os quais, neste caso, trabalham com a ideia de hierarquia. Esta hierarquia foi determinada de acordo com a EE do modelo organizacional.

A hierarquia mostra os papéis conforme sua ordem de autonomia e é baseada em determinadas regras que são importantes para aquela sociedade de agentes onde o papel com posição inferior é sempre subordinado a papéis com posições superiores.

Neste caso, os papéis deixam de ser denominados de papéis sociais para serem chamados de papéis organizacionais, que se tornam componentes proativos do sistema legislador pelo fato de estarem ligados a um conjunto de artefatos, e tendo como principal característica a autonomia.

Esses artefatos são baseados no metamodelo de Agentes e Artefatos ( $A$ \& A) que incorporam um conjunto de metas e planos. Sendo assim, pode-se dizer que esses artefatos são as leis, normas, regimentos, decretos e contratos que irão determinar as ações a serem executadas pelos agentes e demais papéis.

Os artefatos podem ser considerados uma ferramenta que os agentes possuem e que determinam se os mesmos são capazes de manipular, compartilhar e utilizar essas entidades para auxiliar e facilitar na realização de suas tarefas. Além disso, esses artefatos determinam se esses papéis devem executar as normas e planos de ações como se fossem um direito, um dever ou uma proibição.

\section{SIMULAÇÃO DO MODELO DE SISTEMA AVA-SMA ORIENTADO A LEGISLAÇÃO APLICADO AO MOODLE}

O Modelo AVA-SMA orientado à Legislação aplicado ao MOODLE irá notificar os usuários do sistema de sociedade através de um caixa incorporado ao ambiente chamado de box que pode ser considerado um plug-in do MOODLE.

Ao ativar esse plug-in, o Papel Monitor analisará todas as ações dos usuários com base nas regras previamente criadas pelo Papel Legislador e no conjunto de ações que devem ser realizadas pelo sistema no caso de cumprimento ou descumprimento dessas regras.

Ao identificar uma regra com pendência ou que foi cumprida, o Papel Monitor em conjunto com o Papel Notificador irá mostrar uma mensagem nesse box formada pelos seguintes componentes (Figura 3): nome do usuário; mensagem padrão para cada ação, cadastradas previamente; nome da atividade; nome da disciplina; descrição da regra retirada da legislação; data limite para atender a regra, se tiver; link da legislação onde a regra está baseada. 


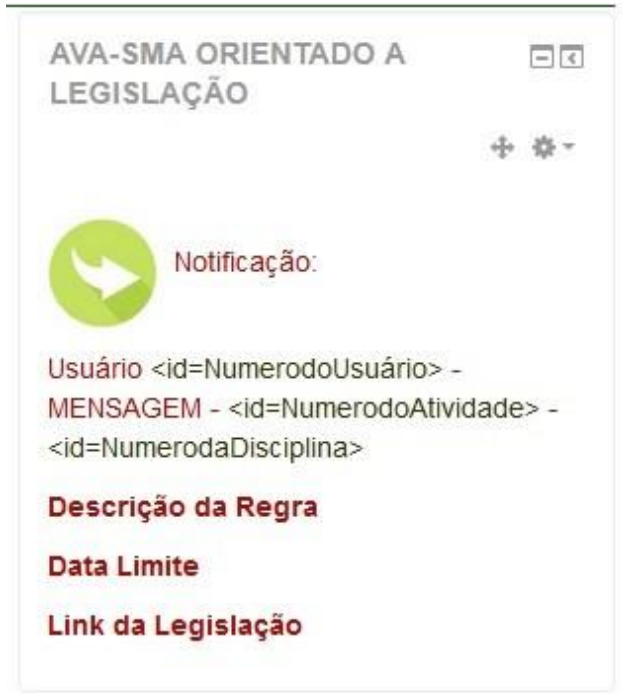

Figura 3. Padrão de mensagem do Papel Notificador

Fonte: Elaborado pelo autor.

Além disso, o Papel Monitor analisará todas as ações que não forem realizadas e o Papel Aplicador irá realizar ações de sanção sobre os usuários do sistema de sociedade que cumprir ou deixar de cumprir a regra dentro do limite estipulado.

O Papel Aplicador sempre encaminhará uma mensagem ao box sobre a ação que foi realizada para os usuários hierarquicamente superiores, conforme especificação deôntica do modelo organizacional SMA, bem como mensagem via e-mail.

A mensagem do aplicador será composta por: nome do Usuário e mensagem padrão para cada ação realizada pelo papel aplicador.

Para a realização dessas simulações, foi utilizado a implementação de interface, utilizando a linguagem PHP, incorporado ao MOODLE.

Como base nessa simulação de interface, a seguir será apresentada um exemplo de como o MOODLE se comporta em relação ao cumprimento ou descumprimento de algumas regras que envolvem o coordenador de curso.

\subsection{Regra CompExp}

Um coordenador de curso ao ser selecionado para exercer a função deve realizar o cadastrado provisório no MOODLE. Nesse caso, o papel atribuído a esse usuário será de visitante. Sendo assim, o mesmo deverá postar no MOODLE os documentos comprobatórios para atuar na função. Esse coordenador de curso, deverá postar dentro do espaço denominado Área de Gestão - Rede e-Tec IF.

Na Figura 4 é apresentado um diagrama que representa a troca de mensagens realizada pelos usuários, bem como as ações realizadas pelo papel aplicador para a Regra CompExp, que será descrita a seguir. 


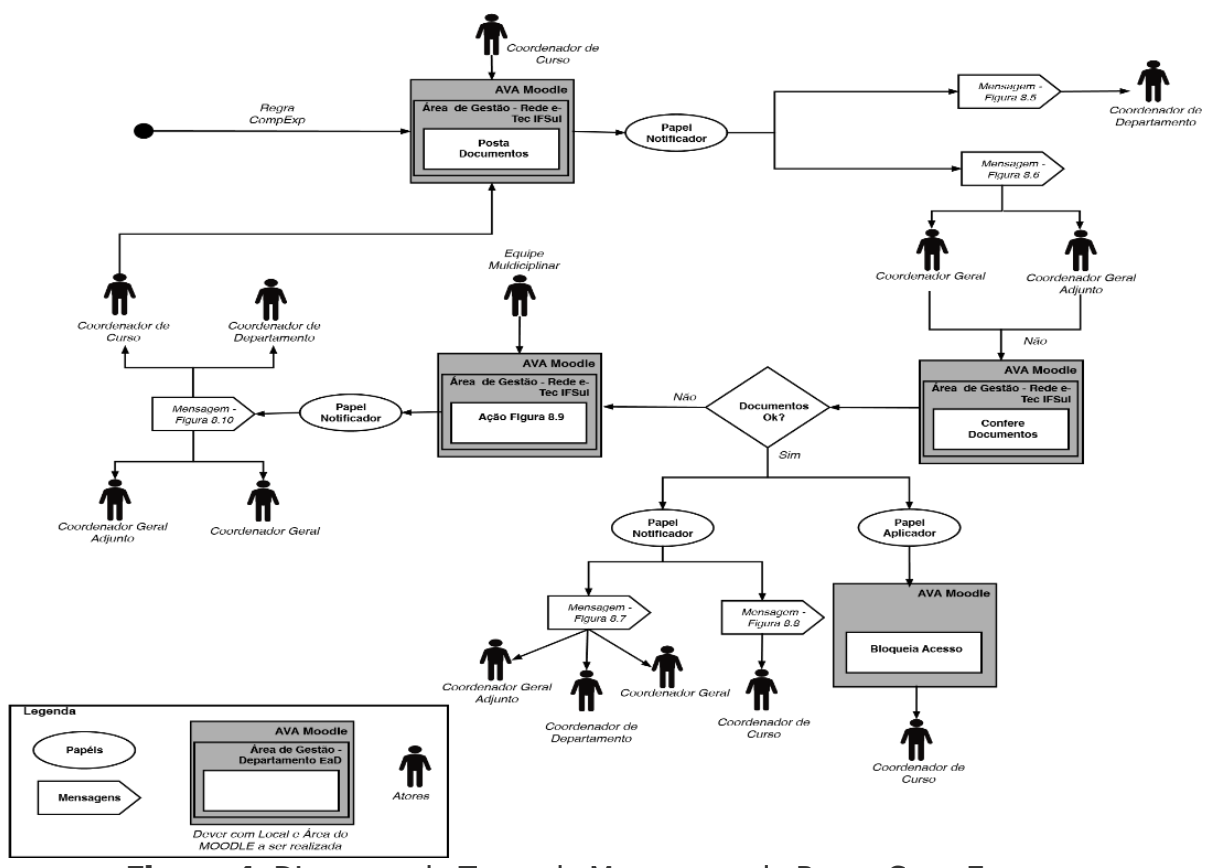

Figura 4. Diagrama de Troca de Mensagens da Regra CompExp

Fonte. Elaborado pelo autor.

Ao postar os documentos exigidos pela legislação, a Coordenação Geral Rede e-Tec Brasil, receberá por meio do Papel Notificador um aviso de que todos os documentos foram postados e estão prontos para a conferência. Além disso, o gestor que está hierarquicamente acima do Coordenador de Curso, neste caso, o Coordenador de Departamento, também receberá uma notificação sobre a entrega dos documentos (Figura 5).

Coordenador Departamento
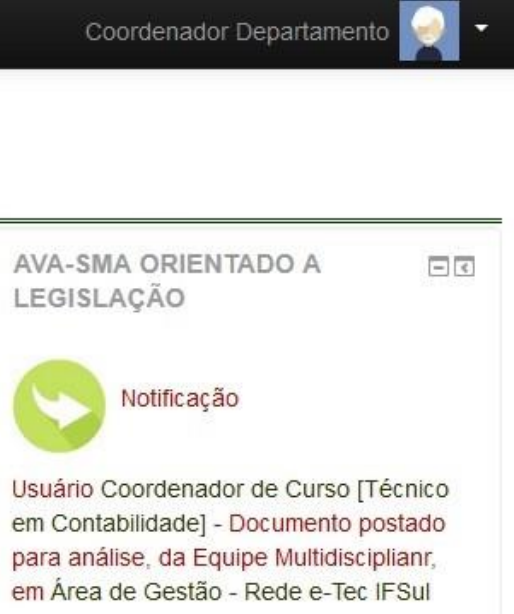

Figura 5. Mensagem do Papel Notificador ao Coordenador de Departamento

Fonte. Elaborado pelo autor.

Sendo assim, a Coordenação Geral faz a conferência manual dos documentos. Se os documentos estiverem todos entregues e sem pendências, o Papel Notificador enviará uma mensagem de retorno a esse usuário enquanto que o Papel Aplicador liberará o acesso em todas áreas do MOODLE, passando o papel de usuário visitante para Coordenador de Curso (Figura 6). 

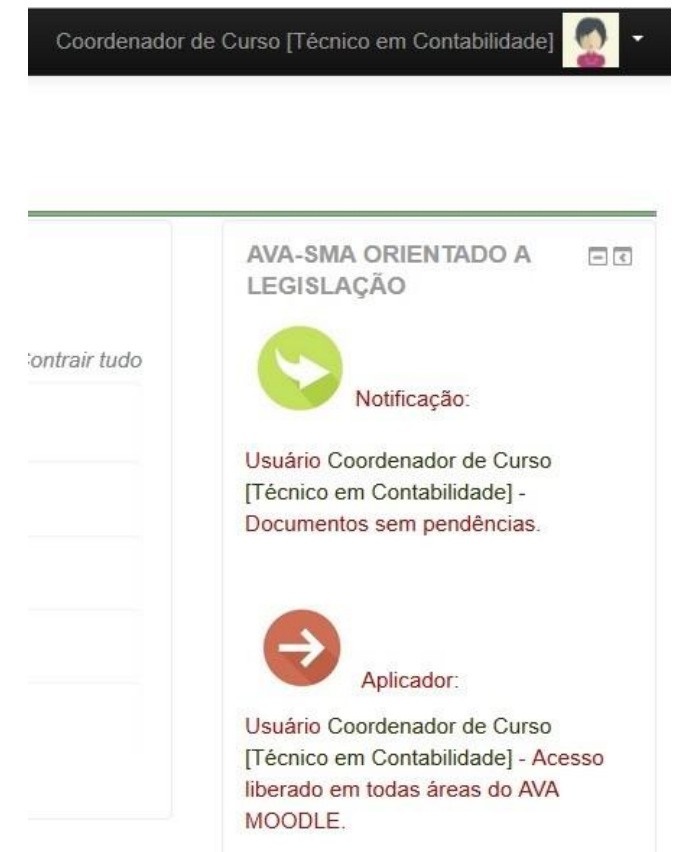

Figura 6. Mensagem do Papel Notificador e do Papel Aplicador ao Coordenador de Curso

Fonte. Elaborado pelo autor.

O Modelo de SMA-AVA notificará também todos que estão hierarquicamente acima do papel Coordenador de Polo.

No caso dos documentos enviados apresentarem pendências, a equipe multidisciplinar irá marcar quais documentos apresentam problemas escolhendo em uma lista qual a pendência existente de acordo com a legislação. Além disso, será determinado um período para o reenvio do documento.

Um exemplo de pendência de documentos pode acontecer quando o coordenador de curso não apresenta o atestado que comprove a experiência de magistério exigida por lei. Nesse caso, a equipe multidisciplinar, liderada pelo coordenador geral e adjunto, escolherá em lista a regra que está pendente.

Após esta etapa, o Papel Notificador enviará tanto ao coordenador de curso quanto ao de departamento uma mensagem com o nome do usuário, a pendência, conforme a legislação, bem como um link para a lei que rege essa regra e o prazo final para a nova postagem do documento.

Caso o documento seja reenviado dentro do prazo e estiver de acordo, o Papel Notificador enviará uma mensagem de retorno a esse usuário, enquanto que o Papel Aplicador liberará o acesso em todas áreas do MOODLE.

Se os documentos pendentes não forem enviados dentro do prazo e/ou não estiverem de acordo com a legislação, o Papel Notificador irá cortar o acesso do usuário e avisar os papéis que estão hierarquicamente acima do papel dessa ação.

\section{APLICAÇÃO DO ALGORITMO KNN AO MODELO AVA-SMA}

Segundo MITCHELL (1997), o algoritmo K-vizinhos mais próximo ou K-nearest neighbors (KNN) é um poderoso algoritmo não-paramétrico de classificação utilizada para a mineração de dados, a fim de realizar o reconhecimento de padrões. 
Para o funcionamento do KNN é necessário um conjunto de exemplos pré-classificados. Com base nesse conjunto de exemplos, um novo padrão K, cuja classe é desconhecida, é comparado com todo o conjunto de exemplos pré-classificados através das relações entre os atributos, ou seja, o classificador KNN procura K elementos de um conjunto de exemplos que estejam mais próximos deste elemento desconhecido procurando o que tem a menor distância.

Assim, é necessário classificar a cada nova instância e buscar as K instâncias que possuem a menor distância em relação a essa nova instância.

Existem várias formas diferentes de calcular essa distância, onde a mais simples é a distância euclidiana (1).

$$
d(p, q)=\sqrt{\sum_{i=1}^{n}\left(\frac{\left(p_{i}-q_{i}\right)}{\left(\max _{i}-\min _{i}\right)}\right)^{2}}
$$

Com o objetivo do modelo proposto anteriormente ser capaz de decidir de forma autônoma quando mostrar mensagens de atrasos a cada um dos usuários, foi implementando dentro do Sistema AVASMA o algoritmo de aprendizagem Knn.

O objetivo de aplicar esse algoritmo ao sistema AVA-SMA é fazer com que o sistema analise ações semelhantes realizadas anteriormente por usuários e com base nisso defina o tempo que o usuário atual deverá ter para realizar a mesma ação. Sendo assim, o papel notificador somente apresentará mensagens caso o usuário ultrapasse esse tempo determinado pelo algoritmo Knn.

Por exemplo, o sistema AVA-SMA junto com o algoritmo Knn realizam uma análise em todas as disciplinas do AVA a fim de determinar o tempo que cada professor leva para corrigir uma atividade. Com base no número postagens, número de questões objetivas e descritivas, carga horária da disciplina e tipo de atividade, o algoritmo Knn determina quais os vizinhos mais próximos, ou seja, determina qual o tempo levado por outros professores para corrigir atividades semelhantes. Caso o professor tenha ultrapassado desse tempo o papel notificador irá avisar que faltam X dias para realizar a correção ou que a atividade está atrasada em $X$ dias para a correção.

\subsection{Fase 1 - Preparação do conjunto de dados de treinamento}

Para testar o funcionamento desse algoritmo desenvolvido em PHP e aplicado ao Sistema AVA-SMA foi necessário extrair da base de dados do AVA MOODLE do IF um conjunto de dados importantes para o funcionamento do algoritmo Knn. Esses dados extraídos foram:

- identificação do Professor;

- carga horária da Disciplina;

- número de atividades por Disciplina;

- data do término da postagem, ou seja, a data limite que o aluno tem para entregar as atividades, visto que o professor só pode começar a correção após essa data;

- data da Finalização da Correção, ou seja, o último dia que o professor realizou a correção das atividades; 
- tipo de Atividade, sendo 1 para fórum, 2 para questionário, 3 para envio de arquivo e 4 para glossário;

- $\quad$ número de questões objetivas;

- número de questões descritivas, as quais levam mais tempo para serem corrigidas;

- número de tentativas, ou seja, o número de alunos que enviaram atividades para serem corrigidas;

- se a correção ocorreu ou não dentro do prazo, sendo 1 para passou do prazo e 0 para não passou do prazo. Para isso, foi utilizada a organização didática que informa que o professor tem de 15 a 20 dias para realizar a correção;

- número de dias que professor levou para realizar a correão com base entre data do término da postagem e a data da Finalização da Correção.

\subsection{Fase $\mathbf{2}$ - Obtenção dos vizinhos mais próximos}

Utilizando o Algoritmo Knn aplicado AVA-SMA foi realizado o teste com o seguinte conjunto de dados (Tabela 2).

\begin{tabular}{|c|c|c|c|c|c|c|c|c|c|c|}
\hline PROFESSOR & CH & $\begin{array}{c}\text { Número } \\
\text { da } \\
\text { Atividade }\end{array}$ & $\begin{array}{c}\text { Término } \\
\text { da } \\
\text { Postagem }\end{array}$ & $\begin{array}{c}\text { Data da } \\
\text { Finalização } \\
\text { da } \\
\text { Correção }\end{array}$ & $\begin{array}{c}\text { Tipo de } \\
\text { Atividade }\end{array}$ & $\begin{array}{c}\text { Número } \\
\text { de } \\
\text { Questões } \\
\text { Objetivas }\end{array}$ & $\begin{array}{c}\text { Número } \\
\text { de } \\
\text { Questões } \\
\text { Descritivas }\end{array}$ & $\begin{array}{c}\text { Número } \\
\text { de } \\
\text { Tentativas }\end{array}$ & $\begin{array}{c}\text { Passou } \\
\text { do } \\
\text { Prazo }\end{array}$ & Dias \\
\hline A & 30 & 1 & $16 /$ mar/15 & $23 /$ mar/15 & 3 & 0 & 1 & 340 & 0 & 7 \\
\hline A & 30 & 2 & $16 / \mathrm{mar} / 15$ & $21 / \mathrm{mar} / 15$ & 3 & 0 & 1 & 338 & 0 & 5 \\
\hline A & 30 & 3 & $16 / \mathrm{mar} / 15$ & $06 / \mathrm{abr} / 15$ & 3 & 0 & 3 & 284 & 1 & 21 \\
\hline A & 30 & 4 & $16 / \mathrm{mar} / 15$ & $27 / \mathrm{mar} / 15$ & 2 & 10 & 0 & 306 & 0 & 11 \\
\hline B & 60 & 1 & $22 / \mathrm{abr} / 15$ & $11 / \mathrm{mai} / 15$ & 4 & 0 & 1 & 306 & 1 & 19 \\
\hline B & 60 & 2 & $16 / \mathrm{mar} / 15$ & $29 / \mathrm{abr} / 15$ & 3 & 0 & 10 & 300 & 1 & 44 \\
\hline B & 60 & 3 & $23 / \mathrm{mar} / 15$ & $31 / \mathrm{mar} / 15$ & 1 & 0 & 1 & 338 & 0 & 8 \\
\hline B & 60 & 4 & $25 / \mathrm{mar} / 15$ & $06 / \mathrm{abr} / 15$ & 2 & 0 & 5 & 217 & 0 & 12 \\
\hline B & 60 & 5 & $06 / \mathrm{abr} / 15$ & $18 / \mathrm{abr} / 15$ & 3 & 0 & 1 & 242 & 0 & 12 \\
\hline B & 60 & 6 & $06 / \mathrm{abr} / 15$ & $24 / \mathrm{mai} / 15$ & 3 & 0 & 1 & 338 & 1 & $? ? ? ? ? ?$ \\
\hline
\end{tabular}

Tabela 2. Conjunto de dados

Fonte. Elaborado pelo autor.

O objetivo foi descobrir quantos dias o professor B levaria para corrigir a atividade 6 . Para isso foi aplicado a seguinte fórmula (2).

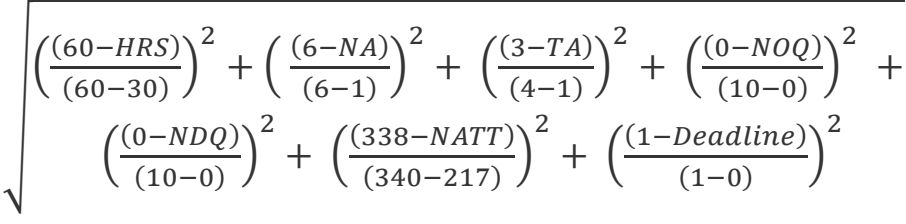

Ao término, foi gerado um SCORE com a pontuação de cada linha do conjunto de dados (Tabela 3). 


\begin{tabular}{|c|c|c|}
\hline PROFESSOR & SCORE & Dias \\
\hline A & 1,732127 & 7 \\
\hline A & 1,624808 & 5 \\
\hline A & 1,262039 & 21 \\
\hline A & 1,829971 & 11 \\
\hline B & 1,085724 & 19 \\
\hline B & 1,24316 & 44 \\
\hline B & 1,343296 & 8 \\
\hline B & 1,548824 & 12 \\
\hline B & 1,284197 & 12 \\
\hline B & 0 & ?????? \\
\hline
\end{tabular}

Tabela 3. Score

Fonte. Elaborado pelo autor.

Com base nesse SCORE foi possível determinar a menor distância, ou seja, o menor SCORE foi de 1,085724. Sendo assim, a média de tempo que o professor B deveria levar para corrigir as atividades é de 19 dias. Se ele ultrapassar esse número o Papel Notificador deverá avisar o mesmo através de mensagens.

\section{CONSIDERAÇÕES FINAIS}

Ao analisar o estado da arte dos AVAs, pôde-se observar que todos atuam como ferramentas de auxílio ao aprendizado, porém nenhum deles controle aspectos de gestão na EaD com suporte à legislação nessa modalidade de ensino. Este trabalho foi desenvolvido com o objetivo de customizar um AVA, propondo um modelo para melhorar a qualidade da gestão administrativa e acadêmica, visto a importância dos gestores manterem o foco na legislação existente para a EAD.

O Modelo de Sistema AVA-SMA orientado à Legislação foi desenvolvido com o objetivo de auxiliar o trabalho manual realizado hoje pelos gestores da EaD no IF em questão utilizado como estudo de caso.

Com o modelo proposto e o protótipo, foi possível traçar direções para uma automatização das funções de controle em relação a legislação, assim, tornou-se possível realizar a sistematização do conhecimento sobre as ações e planos que os agentes devem realizar.

A vantagem desse modelo, ao ser incorporado à interface de um AVA, permite que qualquer usuário que já tenha recebido treinamentos possa utilizá-lo sem grandes dificuldades, visto que o design e a simplicidade do ambiente permitem o uso fácil e agradável, levando ao entendimento e a realização das ações cujos condicionamentos legais costumam ser considerados difíceis de entender.

Em futuros projetos, será possível implementar um número maior de ações, bem como incorporar a parte de relatórios disponíveis aos gestores, com as atividades que envolvam as questões administrativas realizadas ou não pelos os usuários do sistema de sociedade. 


\section{REFERÊNCIAS}

BEHAR, Patricia Alejandra; OLIVEIRA, Silvia de; SCHNEIDER, Daisy. Em busca das interações interindividuais no ROODA. Revista Educação, Porto Alegre- RS, n. 1 (52) p. 169 - 199, Jan./Abr. 2004.

BRASIL. Lei no 9.394, de 20 de dezembro de 1996. Estabelece as diretrizes e bases da educação nacional. Diário Oficial da União, Brasília, DF, 23 dez. 1996.

BRASIL. LEIS, DECRETOS. Decreto no 5.622 de 19/12/ 2005. In: Diário Oficial da União. Brasília (DF): Imprensa Oficial, 20/12/2005.

BRASIL. MEC/SESu. Portaria n. 4.361/04 de 29/12/2004. Dispõe sobre o credenciamento de EaD e demais procedimentos. DOU de 30 de dezembro de 2004, Seção 1, páginas 66/67.

BRITAIN, Sandy; LIBER, Oleg. A Framework for Pedagogical Evaluation of Virtual Learning Environments. Disponível em: <http://www.leeds.ac.uk/educol/documents/00001237.htm/>. Acesso em: 18 Jun 2015.

Dougiamas, Martin. e Taylor, Peter. Improving the effectiveness of tools for Internetbased education, Teaching and Learning Forum, 2000, Curtin University of Technology. Disponível em: <http://Isn.curtin.edu.au/tlf/tlf2000/dougiamas.html>. Acesso em: 18 Dez 2016.

Dougiamas, Martin. Moodle. Disponível em:<http://moodle.org>. Acesso em: 18 Dez 2016.

FOX, Mark. The Tove project towards a common-sense model of the enterprise. Proceedings of the 5th International Conference on Industrial and Engineering Applications of Artificial Intelligence and Expert Systems. London, UK: Springer-Verlag, p. 25-34., ISBN 3-540-55601-X, 1992.

HUBNER, Jomi Fred; SICHMAN, Jaime Simão; BOISSIER, Olivier. Moise+: Towards a structural, functional, and deontic model for mas organization. Proceedings of the First International Joint Conference on Autonomous Agents and Multiagent Systems: Part 1. New York, NY, USA: ACM, p. 501502. ISBN 1-58113-480-0, 2002.

HUBNER, Jomi Fred; SICHMAN, Jaime Simão; BOISSIER, Olivier. Using the Moise ${ }^{+}$for a cooperative framework of MAS reorganisation. Proceedings of the 17th Brazilian Symposium on Artificial Intelligence (SBIA'04), volume 3171 of LNAI, pages 506-515, Berlin, 2004. Springer.

KELSEN, Hans. Teoria Pura do Direito. São Paulo: Martins Fontes, 2009.

MITCHELL, Tom, Machine Learning, McGraw-Hill, 1997.

MUNHOZ, Antônio Siemsen. 0 estudo em Ambiente Virtual de Aprendizagem: um guia prático. Curitiba: Ibpex, 2011.

RUSSELL, Stuart, NORVIG, Peter, Artificial intelligence: a modern approach, Prentice-Hall, Inc., Upper Saddle River, NJ, 1995

WOOLDRIDGE, Michael. An Introduction to Multi-Agent Systems, John Wiley \& Sons, Ltd, 2002. 